\title{
Fatty acid content and composition in edible Ruspolia differens feeding on mixtures of natural food plants
}

\author{
Karlmax Rutaro ${ }^{1,2^{*}}$, Geoffrey M. Malinga ${ }^{2,3}$, Vilma J. Lehtovaara ${ }^{2}$, Robert Opoke ${ }^{3}$, Philip Nyeko ${ }^{4}$, Heikki Roininen ${ }^{2}$ \\ and Anu Valtonen ${ }^{2}$
}

\begin{abstract}
Objectives: To develop successful mass-rearing programs of edible insects, knowledge of the feeds and their influence on nutritional content is critical. We assessed the influence of natural food plants (grass inflorescences) and their mixtures on fatty acid profiles of edible Ruspolia differens. We reared neonate nymphs to adult on six dietary treatments consisting of one, and mixtures of two, three, five, six and eight plants.

Results: The contents of saturated, monounsaturated and polyunsaturated fatty acids, omega-6/omega-3 ratio, and adult body weight did not differ among dietary treatments. However, the composition of fatty acids differed significantly among insects fed on six dietary treatments, but only for the rare fatty acids. Our results demonstrate that even if natural diets (grass inflorescences) do not strongly modify fatty acid contents or compositions of $R$. differens, when reared from neonate nymphs to adults, their $n-6 / n-3$ fatty acid ratio is generally low and thus good for a healthy human diet.
\end{abstract}

Keywords: Africa, Edible insect, Food security, Natural diets, MUFA, PUFA

\section{Introduction}

Ruspolia differens (Tettigoniidae) is one of the most eaten insects in Sub-Saharan Africa with high nutritional and economic potential [1]. Currently, $R$. differens is harvested from the wild during the two annual swarming seasons. To ensure availability of $R$. differens throughout the year, inexpensive diets based on natural plants that could support the small-scale rearing in rural settings of Africa are urgently needed. In the wild, $R$. differens feeds mostly on the leaves, flowers and seeds of grass species, including cereal crops [2, 3], and their nutrient composition depends on the diet [4]. However, the effect of natural plant diets on the nutritional composition of $R$. differens, fatty acids in particular, needs to be investigated.

\footnotetext{
*Correspondence: rutaromax@gmail.com

${ }^{1}$ Department of Biochemistry and Sports Science, Makerere University, P.O. Box 7062, Kampala, Uganda

Full list of author information is available at the end of the article
}

Here, we reared $R$. differens, from neonate nymphs to adult on six plant diets, to know how increasingly diversifying natural diets modify their body weight, and content and composition of their fatty acids. Specifically, we asked: Does the (i) body weight, (ii) content of saturated fatty acids (SFA), monounsaturated fatty acids (MUFA), polyunsaturated fatty acids (PUFA), (iii) $n-6 / n-3$ fatty acid ratio, and (iv) fatty acid composition differ among individuals in the six dietary treatments, between the sexes or is there an interaction between diet and sex? We analyzed the adult insects, which are typically consumed $[1,5]$, in order to provide information that is comparable to previous studies $[3,4,6]$.

\section{Main text \\ Materials and methods \\ Study insects}

The parent population was harvested around the Makerere University Agricultural Research Institute, Uganda. An equal number of sexes were transferred to plastic containers $(24 \mathrm{~cm}$ length $\times 18 \mathrm{~cm}$ width $\times 12.5 \mathrm{~cm}$ 
height). The insects were fed ad libitum on Panicum maximum. Water was provided by inserting wet tissue paper. Females oviposited eggs to $5.3-\mathrm{cm}$ wide $\times 7.1-\mathrm{cm}$ high containers prefilled with wet cotton wool and sand. Eggs were incubated until hatching.

\section{Diet treatments}

The six dietary treatments comprised of one, and mixtures of two, three, five, six and eight grass species inflorescences (Table 1). The grass species were selected based on their acceptance by $R$. differens in preliminary feeding tests (Junes, unpubl. data).

\section{Experimental setup}

The effect of the diet on weight, fatty acid content and composition of $R$. differens was evaluated by rearing 1-2 days old neonate nymphs to adult on the six dietary

Table 1 Composition of grass species inflorescence used in the six dietary treatments

\begin{tabular}{|c|c|}
\hline Treatment name & Composition \\
\hline $\begin{array}{l}\text { One grass species } \\
\text { inflorescence }\end{array}$ & $\begin{array}{l}\text { Congo signal grass Brachiaria ruziziensis R. Germ. } \\
\text { \& C.M.Evrard }\end{array}$ \\
\hline $\begin{array}{l}\text { Two grass species } \\
\text { inflorescence } \\
\text { mixtures }\end{array}$ & $\begin{array}{l}\text { Congo signal grass Brachiaria ruziziensis R.Germ. } \\
\text { \&C.M.Evrard } \\
\text { Ribbon bristle grass Setaria megaphylla (Steud.) } \\
\text { T.Durand \& Schinz }\end{array}$ \\
\hline $\begin{array}{l}\text { Three grass species } \\
\text { inflorescence } \\
\text { mixtures }\end{array}$ & $\begin{array}{l}\text { Congo signal grass Brachiaria ruziziensis R.Germ. } \\
\text { \& C.M.Evrard } \\
\text { Ribbon bristle grass Setaria megaphylla (Steud.) } \\
\text { T.Durand \& Schinz } \\
\text { Nandi grass Setaria sphacelata }\end{array}$ \\
\hline $\begin{array}{l}\text { Five grass species } \\
\text { inflorescence } \\
\text { mixtures }\end{array}$ & $\begin{array}{l}\text { Congo signal grass Brachiaria ruziziensis R.Germ. } \\
\text { \& C.M.Evrard } \\
\text { Ribbon bristle grass Setaria megaphylla (Steud.) } \\
\text { T.Durand \& Schinz } \\
\text { Nandi grass Setaria sphacelata } \\
\text { Antelope grass Echinochloa pyramidalis (Lam.) } \\
\text { Hitchc. \& Chase } \\
\text { Elephant grass Pennisetum purpureum Schumach. }\end{array}$ \\
\hline $\begin{array}{l}\text { Six grass species } \\
\text { inflorescence } \\
\text { mixtures }\end{array}$ & $\begin{array}{l}\text { Congo signal grass Brachiaria ruziziensis R.Germ. } \\
\text { \& C.M.Evrard } \\
\text { Ribbon bristle grass Setaria megaphylla (Steud.) } \\
\text { T.Durand \& Schinz } \\
\text { Nandi grass Setaria sphacelata } \\
\text { Antelope grass Echinochloa pyramidalis (Lam.) } \\
\text { Hitchc. \& Chase } \\
\text { Elephant grass Pennisetum purpureum Schumach. } \\
\text { Rhodes grass Chloris gayana Kunth }\end{array}$ \\
\hline $\begin{array}{l}\text { Eight grass species } \\
\text { inflorescence } \\
\text { mixtures }\end{array}$ & $\begin{array}{l}\text { Congo signal grass Brachiaria ruziziensis R.Germ. } \\
\text { \& C.M.Evrard } \\
\text { Ribbon bristle grass Setaria megaphylla (Steud.) } \\
\text { T.Durand \& Schinz } \\
\text { Nandi grass Setaria sphacelata } \\
\text { Antelope grass Echinochloa pyramidalis (Lam.) } \\
\text { Hitchc. \& Chase } \\
\text { Elephant grass Pennisetum purpureum Schumach. } \\
\text { Rhodes grass Chloris gayana Kunth } \\
\text { Wild finger millet Eleusine indica (L.) Gaertn } \\
\text { Guinea grass Panicum maximum Jaca. }\end{array}$ \\
\hline
\end{tabular}

treatments $\left(23-27^{\circ} \mathrm{C}, 50-60 \% \mathrm{RH}\right.$ and $12 \mathrm{~L}: 12 \mathrm{D}$ photoperiod). Nymphs were individually reared in jars, covered with a netting cloth. The position of the jars in 10 blocks was routinely shuffled to cater for microclimatic variability. Approximately equal amounts of food (two florets) were given (i.e., the single-feed diet received two florets, the two-feed diet received one floret of each plant and so on), and only freshly opened inflorescences were used. The nymphs were fed ad libitum and water provided on wet tissue paper, and diets were replenished after every 3-4 days until moulting to adult. For emerged adults, we recorded the sex and the body weight. Sixty individuals were freeze-dried and five individuals per dietary treatment were randomly selected for fatty acid analyses.

\section{Fatty acid analyses}

Fatty acids were analysed at the Bio-Competence Centre for Healthy Dairy Products (Accreditation EN ISO/IEC 17025:2005), Tartu, Estonia, using direct transesterification [7], with minor modifications [4]. Fatty acid methyl esters were analysed on an Agilent 6890A GC, equipped with a FID detector and an auto sampler [4].

\section{Statistical analyses}

We fitted ANOVA models to analyze whether body weight, content of SFA, MUFA, PUFA, and $n-6 / n-3$ fatty acid ratio of $R$. differens differed among the dietary treatments, sexes, or if there was an interaction between diet and sex. SFA, MUFA and $n-6 / n-3$ were $\ln$-transformed prior to analyses. We fitted PERMANOVA models (type III SS; 999 permutations) in PRIMER-E [8] to test if the composition of fatty acids differed among the dietary treatments, between sexes, and whether there was an interaction between diets and sex (using both untransformed and fourth-root transformed fatty acid proportions). A similarity percentage analysis in PRIMER-E [8] was run to explore which fatty acids contributed most to the dissimilarities. Permutational multivariate dispersion [9] test was used to test if the degree of variability in the relative proportions of fatty acids differed among dietary treatments.

\section{Results \\ Body weight}

The body weight of individuals ranged from $0.41 \mathrm{~g}$ (least diversified) to $0.45 \mathrm{~g}$ (the most diversified diets) but did not differ among the dietary treatments (ANOVA; $\left.\mathrm{F}_{5,18}=2.2, \mathrm{p}=0.098\right)$, between the sexes $\left(\mathrm{F}_{1,18}=2.8\right.$, $\mathrm{p}=0.109)$, and there was no $\operatorname{diet} \times \operatorname{sex}$ interaction $\left(\mathrm{F}_{5,18}=0.8, \mathrm{p}=0.597\right)$.

\section{Fatty acid content}

The content of SFA did not differ between the six dietary treatments (ANOVA; $\left.\mathrm{F}_{5,18}=0.1, \mathrm{p}=0.98\right)$, sexes $\left(\mathrm{F}_{1}\right.$, 
$\left.{ }_{18}=0.1, \mathrm{p}=0.82\right)$ and there was no diet $\times$ sex interaction $\left(\mathrm{F}_{5,18}=1.7, \mathrm{p}=0.18\right)$. MUFA content did not differ between the six dietary treatments (ANOVA; $F_{5,18}=0.3$, $\mathrm{p}=0.89)$, sexes $\left(\mathrm{F}_{1,18}=0.001, \mathrm{p}=0.98\right)$ and there was no diet $\times$ sex interaction $\left(F_{5,18}=1.7, p=0.18\right)$. There was also no difference in the content of PUFA between the six dietary treatments (ANOVA; $\mathrm{F}_{5,18}=0.2, \mathrm{p}=0.96$ ), sexes $\left(\mathrm{F}_{1,18}=0.1, \mathrm{p}=0.79\right)$ and no diet $\times$ sex interaction $\left(\mathrm{F}_{5,18}=1.4, \mathrm{p}=0.26\right)$. Finally, the sexes differed in the ratio of $n-6 / n-3\left(F_{1,18}=4.7, p=0.05\right)$, females having a lower $n-6 / n-3$ ratio (mean $=1.6, \mathrm{SE}=0.2$ ) than males (mean $=2.2, \mathrm{SE}=0.3$ ). However, there was no difference in the ratio $n-6 / n-3$ between the dietary treatments $\left(\right.$ ANOVA; $\left.\mathrm{F}_{5,18}=0.6, \mathrm{p}=0.71\right)$ and no diet $\times$ sex interaction $\left(\mathrm{F}_{5,18}=1.9, \mathrm{p}=0.14\right)$.

\section{Fatty acid composition}

There were no differences in the composition of (untransformed) fatty acids (emphasizing the most common fatty acids) between the dietary treatments (PERMANOVA; pseudo- $\mathrm{F}_{5,18}=0.7, \mathrm{p}=0.66$ ), sexes (pseudo- $\mathrm{F}_{1,18}=0.99$, $\mathrm{p}=0.35$ ) and there was no diet $\times$ sex interaction (pseudo$\left.\mathrm{F}_{5,18}=1.69, \mathrm{p}=0.15\right)$. However, when the fatty acid compositions were fourth root transformed (emphasizing the rare fatty acids), the fatty acid compositions differed among the six dietary treatments (PERMANOVA; pseudo- $\mathrm{F}_{5,18}=3.3, \mathrm{p}=0.001$ ), but not between the sexes (pseudo- $\mathrm{F}_{1,18}=1.4, \mathrm{p}=0.23$ ) and there was no diet $\times$ sex interaction (pseudo- $\mathrm{F}_{5,18}=1.2, \mathrm{p}=0.29$ ). The dietary treatment explained $33 \%$ of the variation in the fatty acid compositions. The differences in compositions were not explained by differing variation in fatty acid composition among diets (PERMDISP; $\mathrm{F}_{5,24}=0.6, \mathrm{p}=0.811$ ). Based on the similarity percentage analysis, Eicosenoic (cis-11-eicosenoic) acid, gadoleic (cis-9-eicosenoic) acid, docosadienoic (cis-13, 16-docosadienoic) acid made the strongest contributions to the dissimilarities in the fatty acid composition across the dietary treatments (fourthroot transformed data). Eicosenoic and docosadienoic acids were more common in less diversified diets whereas gadoleic acid was more common in highly diversified diets (Table 2).

Overall, the PUFAs contributed most to the fatty acid composition followed by MUFAs and SFAs (Table 2). The total PUFAs on dry weight basis ranged from 36 to $44 \%$ across diet treatments (Table 2). The most predominant PUFAs were linoleic acid (21-28\%) and $\alpha$-linolenic acid (12-16\%) (Table 3). The proportion of SFAs ranged from 32 to $33 \%$ with palmitic acid (20-22\%) and stearic acid (8-9\%) being the most predominant fatty acids (Table 2 ). For MUFAs, the range was from 22 to $31 \%$ with oleic acid (20-29\%) being the most predominant (Table 2).

\section{Discussion}

Diversifying natural plant diets (inflorescences of grasses) cannot alter the content and compositions of the most common fatty acids in $R$. differens when reared throughout the entire life-cycle (although the composition of rare fatty acids was altered). The rationale for this might be that when $R$. differens feed on the natural diet, they produce fatty acids through de novo biosynthesis. However, the composition of fatty acids in the wild-harvested sixth instar nymphs of $R$. differens differed significantly when reared for 2 weeks on different mixtures of its natural plants (inflorescences of grasses) [10]. The reason why differences in fatty acid content and composition did not emerge here, when $R$. differens are reared throughout their life-cycle, could be due to the conversion of accumulated fatty acids to other biosynthetic precursors and utilization for other body requirements during insect development $[11,12]$. Linoleic and $\alpha$-linolenic acids, for example, provide the building blocks for making arachidonic acid and eicosanoids [13]. Eicosanoids, though in limited proportions might be an indication of its role in immune defensive mechanisms and reproduction of $R$. differens, as for various insect species [12-14]. The fatty acid profiles in the tissues of insects can change drastically after neonate nymphs' metamorphosise through developmental stages into maturity [14].

The most common fatty acids found included palmitic, stearic, oleic, linoleic and $\alpha$-linolenic acids. With exception of $\alpha$-linolenic acid (12-16\%), other common fatty acids (Table 3 ) had relatively similar proportions to those found in earlier studies [4, 6]. The contents of SFA and MUFA in $R$. differens were not altered by the diversifying natural food plant diets, suggesting that diets offered insects relatively similar SFA and MUFA contents. Fatty acids such as palmitic acid is used as precursors for the biosynthesis of long chain fatty acids [14]. The low content of SFA could suggest that certain MUFAs are synthesised from SFA precursors [14]. Biosynthesis of MUFA and SFA is a common phenomenon in many insect groups [14]. In comparison to [4] that reared neonate nymphs to maturity, the contents of SFA and MUFA in this study were generally low. Possibly the diet offered to $R$. differens in [4] was richer in SFA and MUFA compared to our grass inflorescences. When compared with insects analysed in [15], our samples had relatively low fatty acid content.

Our results show that the ratio of $n-6 / n-3$ fatty acid is not altered by the natural plant diet representing inflorescences of grasses. However, the $n-6 / n-3$ ratio in male $R$. differens was generally higher than in females possibly due to diverse physiological and metabolic functions between male and female or differences 
Table 2 Fatty acid proportions (\%) of $R$. differens feeding on the six gradually diversifying natural diets consisting of one, and mixtures of two, three, five, six and eight grass species inflorescences

\begin{tabular}{|c|c|c|c|c|c|c|}
\hline \multirow[t]{2}{*}{ Fatty acid } & \multicolumn{6}{|c|}{ Dietary treatment } \\
\hline & One grass & Two grasses & Three grasses & Five grasses & Six grasses & Eight grasses \\
\hline C10:0 & $0.00 \pm 0.00$ & $0.00 \pm 0.00$ & $0.00 \pm 0.00$ & $0.09 \pm 0.09$ & $0.00 \pm 0.00$ & $0.00 \pm 0.00$ \\
\hline C12:0 & $0.10 \pm 0.01$ & $0.04 \pm 0.01$ & $0.08 \pm 0.01$ & $0.1 \pm 0.01$ & $0.08 \pm 0.01$ & $0.06 \pm 0.01$ \\
\hline C14:0 & $0.75 \pm 0.01$ & $0.58 \pm 0.09$ & $0.68 \pm 0.07$ & $0.91 \pm 0.18$ & $0.81 \pm 0.09$ & $0.68 \pm 0.15$ \\
\hline C15:0 & $0.32 \pm 0.05$ & $0.29 \pm 0.05$ & $0.33 \pm 0.05$ & $0.38 \pm 0.08$ & $0.24 \pm 0.05$ & $0.23 \pm 0.03$ \\
\hline C16:0 & $20.74 \pm 3.17$ & $20.19 \pm 2.05$ & $19.61 \pm 2.08$ & $19.80 \pm 3.71$ & $22.26 \pm 2.14$ & $22.12 \pm 3.49$ \\
\hline C18:0 & $8.66 \pm 0.90$ & $8.80 \pm 0.49$ & $9.20 \pm 0.83$ & $9.09 \pm 1.34$ & $7.79 \pm 0.81$ & $7.69 \pm 0.78$ \\
\hline $\mathrm{C} 20: 0$ & $1.27 \pm 0.30$ & $1.18 \pm 0.25$ & $1.41 \pm 0.36$ & $1.35 \pm 0.29$ & $0.94 \pm 0.23$ & $1.05 \pm 0.29$ \\
\hline C22:0 & $0.49 \pm 0.14$ & $0.44 \pm 0.11$ & $0.50 \pm 0.13$ & $0.51 \pm 0.14$ & $0.37 \pm 0.14$ & $0.36 \pm 0.13$ \\
\hline C23:0 & $0.03 \pm 0.01$ & $0.02 \pm 0.01$ & $0.01 \pm 0.01$ & $0.01 \pm 0.01$ & $0.03 \pm 0.01$ & $0.03 \pm 0.02$ \\
\hline C24:0 & $0.04 \pm 0.01$ & $0.05 \pm 0.01$ & $0.09 \pm 0.02$ & $0.07 \pm 0.02$ & $0.08 \pm 0.01$ & $0.08 \pm 0.02$ \\
\hline$C 26: 0$ & $0.24 \pm 0.07$ & $0.32 \pm 0.21$ & $0.17 \pm 0.04$ & $0.19 \pm 0.04$ & $0.20 \pm 0.04$ & $0.14 \pm 0.05$ \\
\hline$\sum S F A$ & $32.62 \pm 3.23$ & $31.91 \pm 1.47$ & $32.10 \pm 1.72$ & $32.50 \pm 3.93$ & $32.80 \pm 1.37$ & $32.45 \pm 3.81$ \\
\hline C14:1n5t & $0.00 \pm 0.00$ & $0.00 \pm 0.00$ & $0.02 \pm 0.02$ & $0.02 \pm 0.02$ & $0.01 \pm 0.01$ & $0.00 \pm 0.00$ \\
\hline C14:1n5 & $0.11 \pm 0.05$ & $0.08 \pm 0.02$ & $0.11 \pm 0.03$ & $0.11 \pm 0.04$ & $0.07 \pm 0.01$ & $0.09 \pm 0.04$ \\
\hline C16:1n9 & $0.07 \pm 0.02$ & $0.07 \pm 0.01$ & $0.1 \pm 0.01$ & $0.08 \pm 0.02$ & $0.09 \pm 0.01$ & $0.07 \pm 0.00$ \\
\hline C16:1n7 & $0.96 \pm 0.16$ & $0.76 \pm 0.17$ & $0.66 \pm 0.12$ & $0.85 \pm 0.21$ & $1.34 \pm 0.40$ & $1.15 \pm 0.16$ \\
\hline C17:1n10 & $0.17 \pm 0.12$ & $0.15 \pm 0.05$ & $0.27 \pm 0.11$ & $0.37 \pm 0.10$ & $0.32 \pm 0.11$ & $0.31 \pm 0.10$ \\
\hline C17:1n8 & $0.50 \pm 0.13$ & $0.46 \pm 0.08$ & $0.41 \pm 0.15$ & $0.42 \pm 0.05$ & $0.32 \pm 0.02$ & $0.27 \pm 0.04$ \\
\hline $\mathrm{C} 18: 1 \mathrm{n} 10,12 \mathrm{t}$ & $0.00 \pm 0.00$ & $0.00 \pm 0.00$ & $0.00 \pm 0.00$ & $0.00 \pm 0.00$ & $0.06 \pm 0.03$ & $0.03 \pm 0.02$ \\
\hline C18:1n9t & $0.18 \pm 0.03$ & $0.18 \pm 0.04$ & $0.13 \pm 0.05$ & $0.19 \pm 0.08$ & $0.13 \pm 0.04$ & $0.08 \pm 0.03$ \\
\hline $\mathrm{C} 18: 1 \mathrm{n} 7 \mathrm{t}$ & $0.00 \pm 0.00$ & $0.00 \pm 0.00$ & $0.02 \pm 0.02$ & $0.00 \pm 0.00$ & $0.00 \pm 0.00$ & $0.00 \pm 0.00$ \\
\hline C18:1n9 & $20.46 \pm 2.88$ & $22.28 \pm 2.81$ & $19.51 \pm 2.74$ & $22.32 \pm 3.18$ & $27.25 \pm 3.26$ & $28.60 \pm 2.30$ \\
\hline C18:1n7 & $0.09 \pm 0.02$ & $0.10 \pm 0.01$ & $0.07 \pm 0.02$ & $0.09 \pm 0.02$ & $0.02 \pm 0.01$ & $0.00 \pm 0.00$ \\
\hline C20:1n11,12 & $0.00 \pm 0.00$ & $0.00 \pm 0.00$ & $0.00 \pm 0.00$ & $0.00 \pm 0.00$ & $0.19 \pm 0.05$ & $0.22 \pm 0.07$ \\
\hline C20:1n9 & $0.27 \pm 0.07$ & $0.23 \pm 0.06$ & $0.23 \pm 0.04$ & $0.28 \pm 0.07$ & $0.00 \pm 0.00$ & $0.00 \pm 0.00$ \\
\hline C22:1n9 & $0.00 \pm 0.00$ & $0.01 \pm 0.01$ & $0.00 \pm 0.00$ & $0.01 \pm 0.01$ & $0.00 \pm 0.00$ & $0.00 \pm 0.00$ \\
\hline C24:1n9 & $0.01 \pm 0.01$ & $0.02 \pm 0.01$ & $0.08 \pm 0.07$ & $0.01 \pm 0.01$ & $0.02 \pm 0.01$ & $0.02 \pm 0.01$ \\
\hline$\sum M U F A$ & $22.81 \pm 2.73$ & $24.36 \pm 2.74$ & $21.61 \pm 2.70$ & $24.75 \pm 3.15$ & $29.83 \pm 3.28$ & $30.85 \pm 2.16$ \\
\hline $\mathrm{C} 18: 2 \mathrm{n} 5 \mathrm{c}, 9 \mathrm{t}$ & $0.02 \pm 0.00$ & $0.02 \pm 0.02$ & $0.06 \pm 0.06$ & $0.05 \pm 0.02$ & $0.15 \pm 0.06$ & $0.06 \pm 0.04$ \\
\hline C18:2n6 & $26.27 \pm 6.26$ & $26.95 \pm 2.65$ & $28.45 \pm 2.99$ & $26.82 \pm 6.01$ & $21.03 \pm 2.74$ & $22.87 \pm 5.16$ \\
\hline C18:3n6 & $0.08 \pm 0.02$ & $0.05 \pm 0.01$ & $0.05 \pm 0.02$ & $0.08 \pm 0.02$ & $0.10 \pm 0.02$ & $0.08 \pm 0.02$ \\
\hline C18:3n3 & $16.34 \pm 2.06$ & $15.04 \pm 2.26$ & $15.88 \pm 2.05$ & $13.85 \pm 1.35$ & $14.72 \pm 1.48$ & $12.36 \pm 1.23$ \\
\hline CLA18:2n6t,8c & $0.00 \pm 0.00$ & $0.02 \pm 0.01$ & $0.00 \pm 0.00$ & $0.00 \pm 0.00$ & $0.00 \pm 0.00$ & $0.00 \pm 0.00$ \\
\hline C20:2n6 & $0.00 \pm 0.00$ & $0.00 \pm 0.00$ & $0.00 \pm 0.00$ & $0.00 \pm 0.00$ & $0.09 \pm 0.03$ & $0.07 \pm 0.03$ \\
\hline$C 20: 3 n 3$ & $0.03 \pm 0.01$ & $0.04 \pm 0.02$ & $0.06 \pm 0.06$ & $0.03 \pm 0.02$ & $0.05 \pm 0.02$ & $0.01 \pm 0.01$ \\
\hline$C 22: 2 n 6$ & $0.16 \pm 0.06$ & $0.10 \pm 0.06$ & $0.01 \pm 0.01$ & $0.01 \pm 0.01$ & $0.04 \pm 0.02$ & $0.00 \pm 0.00$ \\
\hline$C 20: 5 n 3$ & $0.01 \pm 0.01$ & $0.00 \pm 0.00$ & $0.00 \pm 0.00$ & $0.00 \pm 0.00$ & $0.02 \pm 0.01$ & $0.06 \pm 0.02$ \\
\hline$C 22: 4 n 6$ & $0.01 \pm 0.00$ & $0.01 \pm 0.01$ & $0.02 \pm 0.02$ & $0.01 \pm 0.01$ & $0.02 \pm 0.01$ & $0.01 \pm 0.00$ \\
\hline$C 22: 5 n 6$ & $0.00 \pm 0.00$ & $0.00 \pm 0.00$ & $0.00 \pm 0.00$ & $0.02 \pm 0.02$ & $0.01 \pm 0.01$ & $0.04 \pm 0.04$ \\
\hline$\sum$ PUFA & $42.90 \pm 5.43$ & $42.21 \pm 3.94$ & $44.43 \pm 3.78$ & $40.81 \pm 6.09$ & $36.08 \pm 4.04$ & $35.50 \pm 5.42$ \\
\hline n6/n3 & $1.85 \pm 0.64$ & $1.98 \pm 0.41$ & $1.89 \pm 0.29$ & $2.03 \pm 0.53$ & $1.45 \pm 0.12$ & $1.90 \pm 0.44$ \\
\hline iso/anteiso & $0.19 \pm 0.06$ & $0.17 \pm 0.03$ & $0.26 \pm 0.07$ & $0.24 \pm 0.07$ & $0.22 \pm 0.05$ & $0.23 \pm 0.07$ \\
\hline C10:1n1c-C11:0 & $0.00 \pm 0.00$ & $0.00 \pm 0.00$ & $0.01 \pm 0.01$ & $0.00 \pm 0.00$ & $0.00 \pm 0.00$ & $0.00 \pm 0.00$ \\
\hline$C 18: \ln 3 c+C 19: 0$ & $1.43 \pm 0.29$ & $1.35 \pm 0.31$ & $1.46 \pm 0.27$ & $1.60 \pm 0.42$ & $0.87 \pm 0.02$ & $0.86 \pm 0.24$ \\
\hline
\end{tabular}

Data are expressed as mean $\pm S E ; n=5 ; S F A$, saturated fatty acids; MUFA, monounsaturated fatty acids; PUFA, polyunsaturated fatty acids; $n 6 / n 3$, ratio of omega- 6 to omega-3 fatty acids; $C$, number of carbon atoms in the fatty acid structure; $c$, cis; t, trans fatty acid; C10:1n1 c-C11:0 and C18:1n3c + C19:0 were unresolved fatty acids, i.e., they were not separated during analysis and thus quantified together 
Table 3 Percentage composition of the most common fatty acids in R. differens compared to previous studies (20102017)

\begin{tabular}{|c|c|c|c|c|c|c|c|c|c|}
\hline \multirow[t]{2}{*}{ Study } & \multicolumn{5}{|c|}{ Common fatty acids } & \multicolumn{3}{|c|}{ Fatty acid groups } & \multirow[t]{2}{*}{ Source } \\
\hline & C16:0 & C18:0 & C18:1n9 & C18:2n6 & C18:3n3 & $\Sigma S F A$ & $\Sigma M U F A$ & $\Sigma$ PUFA & \\
\hline This study & $19.6-22.3$ & 7.7-9.2 & $19.5-28.6$ & $21.0-28.5$ & $12.4-16.3$ & $31.9-32.8$ & $21.6-30.9$ & $35.5-44.4$ & Reared \\
\hline Kinyuru et al. [6] & $31.5-32.1$ & $5.5-5.9$ & $24.6-24.9$ & $29.5-31.2$ & $3.2-4.2$ & $38.3-39.1$ & $26.3-26.6$ & $33.8-34.4$ & Wild harvest \\
\hline Opio [17] & $27.4-31.7$ & $8.3-8.5$ & $40.5-43.4$ & $12.7-16.5$ & $0.72-2.39$ & $36.7-37.3$ & $43.5-46.6$ & $14.4-17.4$ & Wild harvest \\
\hline Fombong et al. [5] & $28.1-28.2$ & $7.8-7.9$ & $44.3-44.4$ & $13.9-14.4$ & $1.39-1.44$ & $37.6-37.8$ & $46.0-46.2$ & $16.0-16.4$ & Wild \\
\hline Lehtovaara et al. [4] & $11.3-35.3$ & $4.9-12.0$ & $19.1-45.3$ & $3.9-37.9$ & $0.4-44.6$ & $16.9-50.8$ & $19.8-48.9$ & $10.1-62.6$ & Reared \\
\hline
\end{tabular}

SFA: saturated fatty acid; C16:0-palmitic acid; C18:0-stearic acid; MUFA: Monounsaturated fatty acid-C18:1n9; PUFA: polyunsaturated fatty acid; C18:2n6-linoleic acid; C18:3n3: a-linolenic acid; values in the table refers to ranges in the percentage composition of individual fatty acids in the studies cited

in utilization of these fatty acids [16]. For example, linoleic and linolenic acids are used in the ovarian development and egg production in females [12]. Overall, for both sexes, the $n-6 / n-3$ fatty acid ratio was less than two, which is within the recommended range [13]. However, this $\mathrm{n} 6 / \mathrm{n} 3$ ratio was low compared to previous studies for both reared [4], and wild-harvested $R$. differens $[5,6,17]$.

Finally, our results showed that the weight of adult $R$. differens was not affected by the studied diets, corroborating our previous findings [10]. However, when fed with artificial diets manipulating fatty acid, carbohydrate and protein contents, differences in the weights emerged [4]. Many previous studies have indicated that the weight of an insect is largely determined by its diet and the development stage [18]. Therefore, it is likely that the fatty acids (or their precursors) were insufficient to build a heavy fat body with the grass inflorescence diets studied. Compared to our previous studies $[19,20]$, feeding on artificial diets generally produced $R$. differens with relatively higher weight $(0.4-0.65 \mathrm{~g})$ than with natural plant diets studied here $(0.41-0.45 \mathrm{~g})$, which could be related to a higher fat content of artificial diets than in grass inflorescences.

\section{Conclusion}

The content and compositions of fatty acids in $R$. differens are not altered by diversifying grass inflorescences diets when reared throughout the entire lifecycle, except for the composition of rare fatty acids. The low $n-6 / n-3$ fatty acid ratio as observed suggest that beneficial $n-6 / n-3$ ratios for humans can be achieved by rearing edible insects on diversifying natural plant diet. Considering the low adult weight compared to previous studies, grass inflorescences alone may not be sufficient feed for $R$. differens.

\section{Limitation of the study}

- Increasing the sample size would offer a better overview of the effect of diet diversification on the factors studied.

\section{Abbreviations}

SFA: saturated fatty acid; MUFA: monounsaturated fatty acid; PUFA: polyunsaturated fatty acid; GC-FID: gas chromatography-flame ionization detector; ANOVA: analysis of variance; PERMANOVA: permutational multivariate analysis of variance; NMDS: non-metric multidimensional scaling; PERMDISP: permutational analysis of multivariate dispersion.

\section{Authors' contributions}

$K R, H R, A V, P N, G M M$ conceived the study. KR collected the data, did statistical analysis and wrote the draft manuscript. KR, HR, AV, PN, GMM, VJL, RO critically revised the manuscript. All authors read and approved the final manuscript.

\section{Author details}

${ }^{1}$ Department of Biochemistry and Sports Science, Makerere University, P.O. Box 7062, Kampala, Uganda. ${ }^{2}$ Department of Environmental and Biological Sciences, University of Eastern Finland, P.O. Box 111, 80101 Joensuu, Finland. ${ }^{3}$ Department of Biology, Gulu University, P.O. Box 166, Gulu, Uganda. ${ }^{4}$ Department of Forestry, Biodiversity and Tourism, Makerere University, P.O. Box 7062, Kampala, Uganda.

\section{Acknowledgements}

We are grateful to the Uganda National Council of Science and Technology for permitting the study (NS. 544) and Makerere University Agricultural Research Institute, Kabanyolo for hosting the project. We also thank I. Mwesige for assistance with fieldwork and feeding experiments.

\section{Competing interests}

The authors declare that they have no competing interests.

\section{Availability of data and materials}

The datasets used and/or analyzed during the current study are available from the corresponding author on reasonable request.

Consent for publication

Not applicable.

Ethics approval and consent to participate Not applicable. 


\section{Funding}

Funding for field study was provided through Academy of Finland grant to HR (14956).

\section{Publisher's Note}

Springer Nature remains neutral with regard to jurisdictional claims in published maps and institutional affiliations.

Received: 17 August 2018 Accepted: 25 September 2018 Published online: 01 October 2018

\section{References}

1. Agea JG, Biryomumaisho D, Buyinza M, Nabanoga GN. Commercialisation of Ruspolia nitidula (Nsenene grasshoppers) in central Uganda. African J Food Agric Nutr Dev. 2008;8:319-32.

2. Bailey WJ, McCrae AWR. The general biology and phenology of swarming in the East African tettigoniid Ruspolia differens (Serville) (Orthoptera). J Nat Hist. 1978;12:259-88.

3. Nyeko P, Nzabamwita PH, Nalika N, Okia CA, Odongo W, Ndimubandi J. Unlocking the potential of edible insects for improved food security, nutrition and adaptation to climate change in the Lake Victoria Basin (Project report no. NR-05-10). Kampala, Uganda: The Lake Victoria research initiative, Inter-University Council of East Africa (IUCEA); 2014.

4. Lehtovaara VJ, Valtonen A, Sorjonen J, Hiltunen M, Rutaro K, Malinga GM, et al. The fatty acid contents of the edible grasshopper Ruspolia differens can be manipulated using artificial diets. J Insects as Food Feed. 2017;3:253-62.

5. Fombong F, Van Der Borght M, Vanden Broeck J. Influence of freezedrying and oven-drying post blanching on the nutrient composition of the edible insect Ruspolia differens. Insects. 2017:8:102.

6. Kinyuru JN, Kenji GM, Muhoho SN, Ayieko M. Nutritional potential of longhorn grasshopper (Ruspolia differens) consumed in Siaya district. Kenya. J Agric Sci Technol. 2010;12:32-46.

7. Sukhija PS, Palmquist DL. Rapid method for determination of total fatty acid content and composition of feedstuffs and feces. J Agric Food Chem. 1988;36:1202-6.

8. Clarke KR, Warwick RM. Changes in marine communities: an approach to statistical analysis and interpretation. 2nd ed. Plymouth, UK: PRIMER-E Ltd; 2001.
9. Anderson M, Gorley RN, Clarke RK. Permanova + for primer: guide to software and statistical methods. Plymouth: PRIMER-E; 2008.

10. Rutaro K, Malinga GM, Lehtovaara VJ, Opoke R, Valtonen A, Kwetegyeka J, et al. The fatty acid composition of edible grasshopper Ruspolia differens (Serville) (Orthoptera: Tettigonoidae) feeding on host plants. Entomol Res. 2018. https://doi.org/10.1111/1748-5967.12322.

11. Karuhize GR. Utilization of fat reserve substances by Homorocoryphus (Orthoptera: Tettigoniidae) during flight. Comp Biochem Physiol Part B Comp Biochem. 1972:43:563-9.

12. Murata M, Tojo S. Utilization of lipid for flight and reproduction in Spodoptera litura (Lepidoptera: Noctuidae). Eur J Entomol. 2002;99:221-4.

13. Simopoulos AP. An increase in the omega-6/omega-3 fatty acid ratio increases the risk for obesity. Nutrients. 2016:8:128.

14. Stanley-Samuelson DW, Jurenka RA, Cripps C, Blomquist GJ, de Renobales M. Fatty acids in insects: composition, metabolism, and biological significance. Arch Insect Biochem Physiol. 1988;5:1-33.

15. Pino Moreno JM, Ganuly A. Determination of fatty acid content in some edible insects of Mexico. J Food Feed. 2016;2:37-42.

16. Subramanyam B, Cutkomp LK. Total lipid and fatty acid composition in male and female larvae of Indian-meal moth and almond moth (Lepidoptera: Pyralidae). Gt Lakes Entomol. 1987;20:10.

17. Opio M. Abundance and nutritional compositions of Ruspolia differens polymorphs from Masaka Uganda. Kampala: Makerere University; 2015.

18. Loveridge JP. Age and the changes in water and fat content of adult laboratory-reared Locusta migratoria migratorioides R. and F. Rhod Zambia Malawi J Agric Res. 1973;11:131-43.

19. Malinga GM, Valtonen A, Lehtovaara VJ, Rutaro K, Opoke R, Nyeko P, et al. Mixed artificial diets enhance the developmental and reproductive performance of the edible grasshopper, Ruspolia differens (Orthoptera: Tettigoniidae). Appl Entomol Zool. 2018;53:1-6.

20. Lehtovaara VJ, Roininen $\mathrm{H}$, Valtonen A. Optimal temperature for rearing the edible Ruspolia differens (Orthoptera: Tettigoniidae). J Econ Entomol. 2018. https://doi.org/10.1093/jee/toy234 (In press).
Ready to submit your research? Choose BMC and benefit from:

- fast, convenient online submission

- thorough peer review by experienced researchers in your field

- rapid publication on acceptance

- support for research data, including large and complex data types

- gold Open Access which fosters wider collaboration and increased citations

- maximum visibility for your research: over $100 \mathrm{M}$ website views per year

At BMC, research is always in progress.

Learn more biomedcentral.com/submissions 